\title{
Participación política de la población afrodescendiente en los procesos de ciudadanización del estado del Cauca, 1853-1863
}

Resumen: El presente artículo aborda las formas de participación de la población afrodescendiente en los procesos de construcción y ampliación de la ciudadanía en el estado del Cauca entre 1853-1863. El argumento central indica que los afrocaucanos, excluidos de la ciudadanía formal, participaron de los procesos de ciudadanización a través de reivindicaciones y demandas ciudadanas de tipo convencional y no-convencional. Esta población usó su capital social para salir de la sombra e incursionar en los asuntos públicos, así como disputar y configurar diversos caminos para la ciudadanización. Palabras clave: afrocacucanos, participación política, ciudadanización, capital social.

\section{Political participation of the Afrodescendant population in the process of citizenship in the state of Cauca, 1853-1863}

Abstract: This article addresses the participation of the Afrodescendant population in the processes of construction and expansion of citizenship in the State of Cauca between 1853 and 1863. The central argument suggests that Afrocauanos, while excluded from formal citizenship, participated in citizenship processes through claims and citizen demands of a conventional and non-conventional type. This population used its social capital to come out of the shadows and venture into public affairs and to dispute and configure different paths for citizenship.

Keywords: afrocacucanos, political participation, citizenship, social capital.

\section{Participação política da população afrodescendente no processo de cidadania do estado de Cauca, 1853-1863}

Resumo: Este artigo aborda as formas de participação da população afrodescendente nos processos de construção e expansão da cidadania do estado do Cauca entre 1853-1863. 0 argumento central indica que os afrocaucanos, excluídos da cidadania formal, participavam de processos de cidadania por meio de reivindicações e demandas cidadãs do tipo convencional e não convencional. Essa população usou seu capital social para sair das sombras e se aventurar nos assuntos públicos, assim como disputar e configurar diferentes caminhos para a cidadania.

Palavras-chave: afrocaucanos, participação política, cidadania, capital social.

Cómo citar este artículo: Fernel Martínez Valenzuela, "Participación política de la población afrodescendiente en los procesos de ciudadanización del estado del Cauca, 1853-1863", Trashumante. Revista Americana de Historia Socia/ 14 [2019]: 124-148.

DOI: 10.17533/udea.trahs.n14a06

Fecha de recepción: 17 de mayo de 2018

Fecha de aprobación: 4 de enero de 2019

Fernel Martínez Valenzuela: Magíster en Ciencia Política por la Facultad Latinoamericana de Ciencias

Sociales [Flacso-Ecuador]. Actualmente adelanta estudios doctorales en Ciencia Política en la misma universidad.

Correo electrónico: femartinezfl@flacso.edu.ec 


\section{Participación política de la población afrodescendiente en los procesos de ciudadanización del estado del Cauca, 1853-1863}

Fernel Martínez Valenzuela

Introducción

Resulta que hubo un negro valiente que era el capitán de todas las insurrecciones [...], le decían "Lujuria"; ese se tomó la hacienda de "Japio" con

un puñado de esclavos libertos, porque había que ir a sacar a los que no querían salir de allí; bueno y dio la casualidad que cuando llegaron los negros, estaba allí todo lo más florido de las damas de Popayán. Entonces, los negros se desquitaron, ya sabrán ustedes cómo, [...] porque Arboleda hacía esto, [...] cuando llegaba y no le gustaba un negrito por cualquier cosa, así chiquito, lo levantaba para arriba y lo esperaba una lanza [...] Entonces los negros le sacaron allá un verso:

El sanguinario Arboleda, mataba negros con furia,

pero las popayanesas, gozáronla con "Lujuria”.

Esta descripción de los hechos acaecidos en la hacienda de Japio, ubicada en el -Valle del Cauca cerca a Caloto, durante el proceso abolicionista hace parte de la disertación del historiador Sabas Casarán Hernández en el primer simposio de la historia y producción bibliográfica del negro en Colombia, realizado entre el 12 y 15 de octubre de 1983. En ella, Casarán nos ofrece una versión desde las acciones contestatarias emprendidas por los negros esclavizados, que resultará útil para luego introducir el tema de la ciudadanía, altamente debatido en las últimas décadas.

Abordar la ciudadanía para el siglo XIX es complejo, y resulta aún más, si se relaciona con la población afrodescendiente. Los estudios han concluido, y casi

1. Sabas Casarán, "Negros en Colombia invisibilidad y presencia”, El negro en la historia de Colombia. Primer simposio sobre bibliografía del negro en Colombia, ed. Fundación Colombiana de Investigaciones Folclóricas (Bogotá: Fondo Interamericano de Publicaciones de la Cultura Negra de las Américas / UNESCO, 1983) 51-62. 
acordado, que no es posible reflexionar sobre el negro desde la ciudadanía republicana, puesto que esta era exclusiva para la élite, excluyente y condicionada bajo ciertos requerimientos. Las conclusiones al respecto aluden a una ciudadanía incompleta, aplazada o negada, aseveraciones que resultan hasta cierto punto válidas, si se piensan solo en perspectiva elitista, republicana y moderna. La dificultad de este argumento versa sobre conclusiones ad hoc que emanan de una ciudadanía concedida "desde arriba" y no como un proceso que también se construye y disputa "desde abajo".

La formación del ciudadano planteada "desde arriba" concibe a la ciudadanía como un estatus jurídico que se les concede a los miembros de pleno derecho de una comunidad política. ${ }^{2}$ La concreción de esta ciudadanía está aparejada a ciertos requerimientos de membresía y a la idea de un Estado capaz de regular las dinámicas sociales y políticas a través de las vías institucionales establecidas.

No obstante, la ciudadanía "desde arriba" dista de ser la única realidad conducente del siglo XIX, pues, desde una perspectiva contextual, la aplicación unívoca de este modelo político-social posee inconsistencias. En primer lugar, porque la idea de un Estado regulador de las dinámicas sociopolíticas choca con la incapacidad del Estado decimonónico para controlar las relaciones sociales y las dinámicas de la vida política, pues los marcos institucionales recientemente establecidos son flexibles, presentan fisuras y las relaciones que establecen son de tipo clientelar. En segundo lugar, porque la idea del poder de ventriloquia, atribuido a la clase hegemónica para encarrilar a los tutorados hacia el modelo ideal de ciudadanía, es cuestionado por las acciones contestatarias de los sectores emergentes; dado que no siempre estuvieron a la espera de concesiones, sino que también conquistaron espacios e hicieron escuchar sus demandas por medio de acciones que interpelaron el statu quo.

En tal sentido, para desentrañar el tipo de prácticas ciudadanas que no encajan con la perspectiva "desde arriba" se propone abordar la ciudadanía desde un enfoque desde abajo. Este se entiende como un "proceso instituido" centrado en redes, vínculos relacionales y prácticas que activan diferentes formas de participación convencional y no convencional en diversos espacios populares públicos. Además, permite analizar las dinámicas que se dan fuera de los escenarios oficiales y la manera en la que se relacionan con el establishment, enfocando al sujeto como reproductor de su propia historia y, desde luego, bajo condiciones heredadas e impuestas por el orden hegemónico. ${ }^{3}$ Lo que lleva a pensar que estas dinámicas logran configurar una ciudadanía alimentada dialécticamente por los procesos formales e informales.

En este orden de ideas, esta investigación pretende dilucidar contingencias y luchas históricas de la población afrocaucana que disputaron o consensuaron los

2. Thomas Marshall, Ciudadanía y clase social (Madrid: Alianza Editorial, 1998) 37.

3. Karl Marx, El dieciocho brumario de Luis Bonaparte (Madrid:Alianza Editorial, 2003) 33. 
mecanismos formales de la ciudadanía. ${ }^{4}$ El propósito es responder a la pregunta: ¿cómo participa la población afrocaucana en los procesos de ciudadanización entre $1853-1863 ?^{5}$

Según Arleison Arcos, "la ciudadanía afroamericana se empieza a construir desde el rechazo y se ejerce desde el levantamiento y la protesta, incluso armada y violenta". ${ }^{6}$ En tal sentido, una vez conquistada la libertad, los afrocaucanos expresaron sus demandas y reivindicaciones por medio de la guerra, pero también por medio de prácticas de sociabilidad que en ocasiones hallaron eco en ideas como igualdad, justicia y derecho. Los nuevos libres vieron la oportunidad de exigir las implicaciones sustanciales de la ciudadanía y no dudaron cuando les fue posible publicitar sus demandas y disputar el acceso y el contenido de la ciudadanía.

Con el fin de dar claridad a las ideas este estudio se divide en dos partes: en la primera se expone de forma sucinta la idea teórica sobre ciudadanía; en la segunda se desentrañan las prácticas de resistencias históricas agenciadas por los afrocaucanos en torno a demandas concretas como la libertad, la tierra, los recursos para la supervivencia y el acceso a la ciudadanía. El objetivo es determinar cómo el entramado histórico de resistencia coincide y se identifica con la retórica de igualdad y libertad que promueve el discurso liberal en el marco de la ciudadanía.

\section{Ciudadanía desde abajo: un enfoque contextual}

La ciudadanía como categoría política emana del proyecto republicano y responde a pretensiones elitistas, se configura como un estatus jurídico concedido con admisión restringida y le da al admitido facultades civiles y políticas, en tanto inhibe su contenido social. Tomas Marshall supuso que la ciudadanía política se consolidó para Inglaterra en el siglo XIX, proceso que también ocurrió en los Estados latinoamericanos, mientras que la ciudadanía social debió esperar el siglo XX para ver la luz. Si aceptamos esta secuencia de la ciudadanía, tendremos licencia para suponer que el actor social estuvo inerme e inconsciente en un escenario republicano estrictamente de amos y señores.

La secuencia de ciudadanía planteada por Marshall imposibilita observar los procesos sociales durante la época decimonónica. De ahí la pertinencia de un enfoque desde abajo que entiende a la ciudadanía como un proceso y no como una

4. El concepto afrocaucano se emplea no como una categoría identitaria, sino como una categoría nominal para referenciar al negro. "En este texto se usa el término 'negro' aludiendo a su significado como categoría racial/social del siglo XIX, que además de basarse en la pigmentación de la piel para hacer una generalización sobre las personas, les adjudica el sitio 'más bajo de la pirámide social"”. Orián Jiménez Meneses y Edgardo Pérez Morales, Voces de esclavitud y libertad. Documentos y testimonios. Colombia, 1701-1833 (Popayán: Universidad del Cauca, 2013) 490.

5. Entiéndase por ciudadanización el proceso de construcción y ampliación / constricción de la ciudadanía moderna.

6. Arleison Arcos, Ser como ellos: Esclavización, cimarronaje y republicanismo en el siglo XIX en Colombia (Medellín: El Colectivo de Investigaciones Afrocolombianas, 2014) 54-55. 
categoría, y contextualice las dinámicas y prácticas de ciudadanización. Margaret Somers retomando a Polanyi "induce a reconsiderar la definición de ciudadanía, dejando de centrarse en el estatus y abordándola como un 'proceso instituido", pues considera que "analíticamente, el centrarse en el estatus está vinculado a individuos y categorías mientras que un 'proceso instituido' se centra en redes de pertenencia y relacionalidad", elementos que "bajo ciertas condiciones de lugar, cultura política y participación se podrían transformar en derechos". ${ }^{7}$

Por su parte, Norbert Elias retoma el concepto de proceso civilizatorio y analiza cómo las coacciones sociales externas poco a poco se van transformando en autoconcepciones del individuo y el grupo. ${ }^{8}$ La racionalidad y la voluntad como base del proceder de los individuos en muchos de los casos no es producto de una planificación o intencionalidad predeterminada, sin embargo, progresivamente estructuran lógicas y pautas de comportamiento racionales. Sobre esta idea es posible observar cómo la población afrocaucana se apropia del concepto de ciudadanía y lo esencializa con demandas y reivindicaciones sociales, que de acuerdo a la configuración social — espacio, tiempo y agente- asimilan, resisten o abandonan la propuesta de ciudadanía republicana.

Apoyados en la propuesta de estos autores, se plantea que la ampliación de ciudadanía desde una perspectiva contextual debe contener al menos tres elementos fundamentales: tiempo, espacio y agencia. Con relación al tiempo, Margaret Somers sostiene que desde un enfoque histórico es posible reconocer la coexistencia de dinámicas de participación ciudadana civil, política y social más allá de los mecanismos convencionales.

En cuanto al espacio, la autora insiste en abandonar la dicotomía entre lo nacional y lo local en el marco de las prácticas ciudadanas. Esta propuesta permite concebir la ciudadanía no como un patrón dado desde un centro / nacional o esfera pública oficial, sino como una construcción que integra practicas ciudadanas centro / periferia en esferas populares públicas locales y regionales. Es posible identificar una esfera popular pública cuando al menos se conjugan tres elementos: 1) una condición de exclusión que limita a un colectivo de disfrutar ciertos beneficios - servicios, participación y toma de decisión-, que genera conflicto y produce demandas reivindicativas; 2) la existencia de un capital social con potencial asociativo y de incidencia en los asuntos públicos; ${ }^{9}$ 3) la capacidad de publicidad

7. Margaret Somers, “La ciudadanía y el lugar de la esfera pública: un enfoque histórico”, Ciudadanía: justicia social, identidad y participación, comps. Soledad García y Steven Lukes (Madrid: Siglo XXI, 1999) 227-228.

8. Norbert Elias, El proceso de la civilización: investigaciones sociogenéticas y psicogenéticas (México: Fondo de Cultura Económica, 2015).

9. Putnam define el capital social como "las conexiones entre individuos, las redes sociales y las normas de reciprocidad y confianza que de ella surgen". Tres elementos establecen esta definición: redes, entendida como los vínculos relacionales que se tejen en torno a una condición, un espacio o unos objetivos; normas, las cuales pueden ser escritas o no, que aluden a prácticas consuetudinarias, culturales o conductuales que fijan marcos de comportamientos; de acuerdo al grado de confianza es posible determinar el grado de cohesión, eficiencia y efectividad de un 
- convertir los asuntos privados en públicos - para conquistar voz en espacios negados y elaborar formas de participación que expresen autoconcepciones del mundo.

En lo que respecta al agente, el sujeto social es estudiado y categorizado en términos de clase. Esta tesis excluye de las prácticas ciudadanas elementos como género, etnia y cultura, de ahí la necesidad de un enfoque en el que prime el agente antes que la categoría. ${ }^{10}$

Cada uno de estos elementos configuran el enfoque contextual de la ciudadanía desde abajo, o ciudadanía activa como le llama Bryan Turner. ${ }^{11}$ Esta propuesta rompe con la secuencia de la ciudadanía propuesta por Marshall para el caso de Inglaterra, y prima la alternabilidad de los procesos políticos, sociales y civiles en un contexto siempre alterado como lo fue el siglo XIX. El período republicano estuvo atravesado por luchas intestinas en las cuales la estructura del Estado, el sentimiento nacional y la figura del ciudadano aún eran difusas. Es aquí donde el ejercicio del actor social irrumpe con fuerza, cuestiona el statu quo y aprovecha las ventanas de oportunidad política para insertarse o desvincularse del orden hegemónico. $^{12}$

Surgen entonces preguntas tales como: ¿eran ciudadanos los afrodescendientes, una vez abolida la esclavitud? ¿Significó la libertad el paso a la ciudadanía? ¿Fueron manipulados o diseñaron estrategias de participación? ¿Participaron en las agendas públicas y en las dinámicas políticas? Todos estos interrogantes comenzaron a ser parte de los estudios sobre ciudadanía y esclavitud en el siglo de la política, como llama Elías Palti al siglo XIX. ${ }^{13}$

Uno de los pioneros en abordar esta relación ciudadanía y esclavitud fue Frank Tannenbaum en su estudio titulado Slave and Citizen. ${ }^{14}$ En esta obra señala que la diferencia entre Estados Unidos y América Latina fue la condición legal y moral de la esclavitud. Por su parte, Jochen Kemner publicó en 2012 un estudio donde se pregunta: “¿Eran ciudadanos los afrodescendientes libres en las sociedades esclavistas?", su respuesta alude a las luchas afrodescendientes como una evidencia del forcejeo por la ampliación de la ciudadanía. ${ }^{15}$

En el caso de Brasil, Carvalho plantea que el paso a un modelo republicano consensuado hizo posible que el Estado ampliara la ciudadanía a todos los hombres libres y nacidos en el territorio. Este autor rescata la idea de Bryan Turner de

grupo determinado, así como la potencialidad en torno a sus objetivos. Robert Putnam, Bowling Alone. The Collapse and Revival of American Community (Nueva York: Simon and Schuster, 2000) 56.

10. Somers 220.

11. Bryan Turner, "Outline of a Theory of Citizenship”, Sociology 24 (1990) 189-217.

12. Charles Tilly, “¿De dónde vienen los derechos?”, Revista Sociológica 55 (2004): 273-300.

13. Elías Palti, El tiempo de la política. El siglo XIX revisitado (Buenos Aires: Siglo XXI, 2007).

14. Frank Tannenbaum, Slave and Citizen: The Negro in the Americas (Boston: Beacon Press, 1946).

15. Jochen Kemner, “¿Eran ciudadanos los afrodescendientes libres en las sociedades esclavistas? Cuba, Brasil y Estados Unidos en el siglo XIX”, Revista Ecuatoriana de Historia 36 (2012): 9-38. 
ciudadanía de abajo hacia arriba y viceversa, para afirmar que "la tradición portuguesa es responsable de un estilo de ciudadanía construida desde arriba hacia abajo, en la que predomina el tipo súbdito ciudadano". ${ }^{16}$

Para el caso colombiano los estudios producidos se interesan en las formas y los medios empleados por los afrocolombianos para insertarse en la sociedad y en sus procesos políticos y económicos. Existe una primera literatura que se ocupó de las dinámicas esclavistas entre finales del siglo XVIII y principios del XIX, como el trabajo de German Colmenares sobre Popayán esclavista y el de Jaime Jaramillo Uribe titulado "Esclavos y señores en la sociedad colombiana del siglo XVIII". ${ }^{17}$ Otros de marcada importancia fueron los estudios sobre el fenómeno abolicionista como el de Eduardo Posada y Hermes Tovar Pinzón donde prevalece la tendencia a mostrar los obstáculos que impidieron consolidar la ciudadanía efectiva para los afrocolombianos, y llegan a conclusiones como "ciudadanía aplazada", "libertad sin ciudadanía", "ciudadanía incompleta", "ciudadanía negada", entre otras. ${ }^{18}$ Cartagena como factoría de esclavos ha sido estudiada por investigadores como Aline Helg y Alfonso Múnera. ${ }^{19}$ También el suroccidente colombiano es objeto de estudios como el adelantado por James Sanders y los esfuerzos de Alonso Valencia Llano, Mateo Mina y Francisco Zuluaga que, desde estudios específicos sobre el Patía, el Valle, Chocó, la región el Cauca, han ampliado el debate sobre los mecanismos participativos empleados por los afrocaucanos para disputar y ampliar la ciudadanía. ${ }^{20}$

16. José Murilo Carvalho, "Dimensiones de la ciudadanía en el Brasil del siglo XIX", Ciudadanía política y formación de las naciones. Perspectivas históricas de América Latina, coord. Hilda Sábato (México: El Colegio de México, 1999) 324-325.

17. German Colmenares, Popayán: una sociedad esclavista, 1680-1800 (Bogotá: La Carreta, 1979); Jaime Jaramillo Uribe, "Esclavos y señores en la sociedad colombiana del siglo XVIII", Anuario Colombiano de Historia social y de la Cultura 1 (1963): 3-62.

18. Eduardo Posada, “Abolición de la esclavitud”, Revista Jurídica 176 (1925): 126-133; Hermes Tovar Pinzón y Jorge Tovar Mora, El oscuro camino de la libertad. Los esclavos en Colombia, 1821-1851 (Bogotá: Universidad de los Andes, 2009).

19. Aline Helg, "Raíces de la invisibilidad del afrocaribe en la imagen de la nación colombiana: independencia y sociedad, 1800-1821", Museo, memoria y nación. Misión de los museos nacionales para los ciudadanos del futuro, comps. Gonzalo Sánchez y María Emma Wills (Bogotá: ICANH / IEPRI, 2000); Alfonso Múnera, El fracaso de la nación: región, clase y raza en el Caribe colombiano (1717-1821) (Bogotá: Banco de la República, 1998).

20. James Sanders, Contentious Republicans, Popular Politics, Race, and Class in Nineteenth Century Colombia (Durham / Londres: Duke University Press, 2004); Alonso Valencia Llano, Dentro de la ley. Fuera de la ley. Resistencias sociales y políticas en el Valle del Cauca. 1830-1855 (Cali: Centro de Estudios Regionales Región / Universidad del Valle, 2008); Mateo Mina, Esclavitud y libertad en el valle del río Cauca (Bogotá: Fundación Rosca de Investigación y Acción Social, 1975); Francisco Zuluaga, Guerrilla y sociedad en el Patía. Una relación entre clientelismo político y la insurgencia social (Cali: Universidad del Valle, 1993). 


\section{Ciudadanía en disputa: participación política afrocaucana}

Para observar en detalle la participación afrocaucana en los procesos de disputa y ampliación de la ciudadanía es necesario entender la participación política como "la actividad convencional y no-convencional, agenciada por particulares individuales o colectivos, para incidir en los asuntos públicos y la toma de decisiones del gobierno, propiciando el cambio sociopolítico o resistiéndolo". ${ }^{21}$ Esta definición va más allá de lo que canónicamente se entiende por participación política - la incidencia directa de particulares o mediante sus representantes en los asuntos del gobierno a través de vías institucionales como el voto-, y asume la arena de lo público como potenciales espacios politizados desde donde se desprenden diversas formas de participación no convencionales. Hugo Quiroga resume lo dicho de esta manera: "Lo que sabemos también es que la vida pública no se agota con la participación en los canales políticos tradicionales, partidos, comicios, parlamentos, porque la esfera pública [...] es un dominio más amplio en el que tienen cabida todos los asuntos que pueden ser comunes". ${ }^{22}$

El potencial político de los afrocaucanos no se limitó a la comprensión de categorías o a la obtención de titularidades, sino que aludió a un proceso complejo que combina esta obtención de titulares con fuertes nociones de contenido social y económico. Este proceso involucró la participación política a través de las guerras, de los eventos de protestas agenciadas por cuadrillas de libertos, la participación política asociativa canalizada mediante las sociedades democráticas y la participación electoral a través del voto y la incidencia en las jornadas electorales.

\subsection{Guerra civil: "entre la acción social y la participación delictiva"}

Sobre el tema de las guerras el investigador Charles Tilly señala que estas son las ventanas de oportunidad política desde donde se emiten reivindicaciones viables, se negocia y se interpela al poder hegemónico.Y en efecto, las luchas y las guerras atravesaron todo el siglo XIX y alteraron el orden de la Nueva Granada y del estado del Cauca. La causa central de los conflictos, específicamente en el Cauca, abrigaba el antagonismo entre señores y esclavos.

Las constantes luchas libradas entre esclavos, negros libres y señores esclavistas hicieron de la milicia una opción para la participación civil y política de los esclavos y un problema para los amos. A esto se refiere Alfonso Valencia Llano cuando dice que:

los blancos pobres, los mestizos, los esclavos y libertos libres, huidos o sujetos a las haciendas — conocidos genéricamente en la región caucana como los negros-, aprovecharon las guerras

21. Samuel Huntington y Joan Nelson, No Easy Choice. Political Participation in Developing Countries (Cambridge: Harvard University Press, 1976) 127.

22. Hugo Quiroga, "Ciudadanía y espacio público. Debates y perspectivas”, Revista Venezolana de Ciencia Política 27 (2005): 5-32. 
civiles que se realizaron a lo largo del siglo XIX para conquistar los espacios políticos y sociales que los sectores más señoriales de la élite caucana les negaba. Esto fue posible cuando los políticos caucanos más libres recurrieron a ellos, como fuerza armada para dirimir sus conflictos por el poder, y, ellos, a su vez, aprovecharon la situación para medrar económicamente, para ascender socialmente. ${ }^{23}$

La Guerra de los Supremos en su versión ortodoxa establece la clausura de un par de conventos en Pasto como la gota que derramó el vaso, pero hacer una lectura simplista de este enfrentamiento es perder de vista la cadena de conflictos latentes que en momentos de rupturas emergieron con fuerza. La importancia de esta guerra para el Cauca versa sobre tres elementos básicos: es contemporánea al cúmulo de leyes que inhibe y distiende el proceso abolicionista; emana de un conflicto esencialmente racial, y configura una alianza entre la población afrocaucana y políticos integrantes del partido liberal como el caudillo José María Obando.

La Guerra de los Supremos para el Cauca fue más que una guerra religiosa o guerra de élites, en esencia fue una guerra racial. La inclusión de los negros en el bando liderado por José María Obando, tras el llamado hecho a los negros del Patía, generó un desorden social promovido por las fugas de los esclavos de las haciendas del Valle del Cauca.

Los amos intentaron contener las huidas exigiendo que se les devolvieran sus esclavos tal como lo registra la petición de Antonio Fernández, albacea nativo de Tejada, cuando solicita se le devuelva el negro José Joaquín, esclavo de la testamentaria, "que se halla actual de soldado en dicho escuadrón (del Patía), fue esclavo del citado Señor Antonio Fernandez, y recidente en la hacienda que mantenia este en tapiales, en la jurisdicion de mercaderes; que tambien le consta no haber sido pagado el valor de este, ni rescatadose el por si". ${ }^{24}$ Como este caso, se registra el de Cruz Uribe y Ricaute, albacea de su padre José Nadal Uribe, quien indica que "de la hacienda de Cactipay, de la pertenencia de mi padre se fugo un esclavo llamado Juan, i ahora le he encontrado de soldado en el batallón que esta de guarnición, i no habiendo sido precentado del modo que designan las leyes ni manumitido, espero se sirva U.d. mandar se me entregue como una propiedad de mi casa" ${ }^{25}$

Ante tal situación y presionado por los señores esclavistas, Obando decretó el 1 de abril de 1841:"Artículo 1: se suspende la admisión de los esclavos al servicio de las armas en las provincias del Cauca y Buenaventura" ${ }^{26}$ A pesar de los intentos de los amos y del mencionado decreto, las huidas se incrementaron considerablemente bajo el pretexto del servicio militar. "Los temores parecieron confirmarse

23. Valencia 39.

24. ACC, Popayán, Fondo República, Militar-Civil, signatura 6327 (Rep. M I -6 mg).

25. ACC, Popayán, Fondo República, Militar-Civil, signatura 6176 (Rep. J IV -22 cv).

26. Citado en Valencia 92. 
cuando Obando ocupó Quilichao donde logró reunir más de 900 negros voluntarios que eran auxiliados por otros de la vecina población de Caloto". ${ }^{27}$

La fluidez de la relación entre el político Obando y los negros de la región del Cauca posibilita la incursión de este grupo en el escenario político. Este nexo para la élite señorial era "abominable” e inadmisible. En su escrito, Ramón Mercado, uno de los representantes caucanos en el senado de la república, denunció:

Que José María Obando [...] levantó el grito de la rebelión contra el Gobierno, y proclamando los principios más escandalosos de desmoralización, tales como remisión de deudas, comunidad de tierras y libertad de esclavos, se puso al frente de una partida de malvados, que consiguió aumentar considerablemente con el cebo de la rapiña y del desorden en que puso a la provincia de Pasto y Parte de Popayán. ${ }^{28}$

La identificación de las cuadrillas de esclavos y libertos con las ofertas hechas por Obando: tierra, libertad e inclusión en la vida republicana, puede leerse como tradicionalmente se ha hecho y afirmar que fueron manipuladas por un político. Sin embargo, si hacemos una lectura a contrapelo, es evidente que la fuerza social existente en las provincias de la región del Cauca no fue engendrada por el político, pues como mencionan los representantes a la cámara por Almaguer y Juan Solís, Manzano y Fernando de Zuñiga: "La Provincia de Popayán [...] está llena de bandoleros y ladrones: apenas puede viajarse por ellas, principalmente en la parte de su territorio donde hay esclavos, porque a nadie obedecen, a nadie respetan". ${ }^{29}$ Es claro que la información está cargada de un contenido despectivo con relación a la actitud de los esclavos, pero más allá de eso también deja ver una fuerza social censurada.

No obstante la represión del movimiento obandista, la acción social manifestada había dado muestras de no detenerse ante la derrota, pues las nociones de justicia y derecho adquiridas robustecían las demandas de los esclavos y libertos. En Caloto, terminada la Guerra de los Supremos, continuaron las incursiones, toda vez que en 1843 las cuadrillas se sublevaron y atacaron a un grupo de soldados y "saquearon las haciendas de Japio y Quebradasca, dando gritos de libertad y proclamando a José María Obando, mientras que otra cuadrilla había aparecido en la Bolsa robando ganados". 30

La acción social de las cuadrillas fue estigmatizada como delictiva, ya que estos grupos "se sepultaban en los bosques que contenían más de cuatrocientos bandoleros, de donde salen diariamente a cometer toda clase de depredaciones". ${ }^{31}$ Sin embargo, ya sea vinculados con los estamentos militares del gobierno o con las tropas sublevadas, la guerra fue una ventana de oportunidad política para emitir

\footnotetext{
27. Valencia 94.

28. Valencia 105.

29. Valencia 106-107.

30. Valencia 109-110.

31. Valencia 108.
} 
voces reivindicativas, tal como lo demuestra el caso de Hilario Hurtado, esclavo que prestó su servicio militar y al regresar a su localidad en la provincia de Popayán su amo Rafael Hurtado Carrejo le demandaba volver a la servidumbre:

Hilario Hurtado de este vecindario ante U. con el respeto debido paresco y digo que en el año de 1841 fui formado como continjente y destinado al ejercito en clase de soldado, desde cuyo tiempo servi en el escuadron $n^{\circ} 3$ de línea, hasta que se me declaro inútil pa el servicio por haberme quebrado de las nicles (nigles): seme expedio mi licencia absoluta y hoy [...] me sorprende el señor Rafael Hurtado Carrejo, queriéndome hacer su esclavo, contra la ley, yo servi dos años en el ejercito veterano, y desde el momento que fui filiado, y me inutilisé en el servicio adquri mi libertad, y como se quiere privar de este bien inestimable, yo ocurro a este jusgado de U. pa que en vista de la licencia [...] declare que he obtenido mi libertad, y que no pertenesco a la propiedad de los hurtados..$^{22}$

Ante la demanda impuesta por Hilario Hurtado, el juez del caso declaró que "no sería justo obligarlo a continuar en su clase de esclavo" y "que según lo espresado el mismo Hurtado, reconoció el derecho que su esclavo había adquirido a su libertad, cuando por primera vez lo reconvino después del licenciado", por tal razón "se declara libre a Hilario Hurtado, debiéndose indemnizar de su valor a Rafael Hurtado, de los fondos de manumisión". ${ }^{33}$ El juez en su declaración aludía a la justicia y al derecho adquirido por el esclavo luego de haber peleado en la guerra. Estos dos elementos hablan de la clara conciencia y del conocimiento que los esclavos y libertos ya tenían de los mecanismos de hecho y derecho para reivindicar sus demandas.

En síntesis, es posible afirmar varios elementos: primero, la Guerra de los Supremos fue decisiva en la región del Cauca por ser un conflicto de índole racial más que religioso; segundo, el contexto abolicionista y antiabolicionista aunó en la configuración de oportunidades políticas, y tercero, se logró vincular la acción social con la oportunidad política del conflicto. En otro orden de aspectos es posible señalar que la guerra aceleró la liberación de los esclavos bajo la modalidad de fugas, las cuales se internaron en espacios marginales y, desde allí, generaron resistencias a la subordinación, que se denominaron desde arriba como acciones delictivas y que vistas desde abajo se consideraban como acción social legítima. Por último, y no menos importante, se afirma que la guerra "estableció una relación entre participación política popular, insurgencia social y delictiva”, ${ }^{34}$ cuyos actores principales eran los negros esclavos y libertos.

\subsection{Participación en eventos de protestas: "de esclavos a bandidos"}

Las acciones y protestas emprendidas por las cuadrillas de esclavos estuvieron presentes desde la época colonial, pero en el período republicano se manifestaron con

32. ACC, Popayán, Fondo República, Manumisión, signatura 4031 (Rep.J III -8 em).

33. ACC, Popayán, Fondo República, Manumisión, signatura 4031 (Rep.J III -8 em).

34. Valencia 113. 
mayor intensidad. La relajación de los lazos de subordinación y control alcanzaron niveles críticos que convirtieron a las provincias del sur en un escenario prácticamente invivible.

En los primeros años republicanos es notable la intensificación de los desafios a los señores-amos y la resistencia a medidas judiciales que procuraban controlar la acción social de los grupos de esclavos y negros libres. El caso ocurrido con la cuadrilla de Salinas en Tuluá es ilustrativo; allí intentaron vulnerar la seguridad de la cárcel de Tuluá para liberar a cuatro esclavas integrantes de esta cuadrilla:

a virtud de haber aprendido el alcalde parroquial del distrito de Bugalagrande, cuatro mujeres que se hallaban con los esclavos i libres prófugos en la salina del finado señor Vicente Rosines, fueron remitidas al jefe político del canton de Tuluá, sucediendo en el transito que el conductor que lo era el juez parroquial José María Gonzales fue atacado por Antonio Chilindrin,Vicente López i Manuel María Rivas, con el objeto de dar la libertad a las esclavas [...] no habiendo estos logrado su intento, aun cuando Antonio Chilindrin descargó al juez un garrotaso, las esclavas fueron siempre llevadas a su destino $[\ldots]$

En este Estado la noche del 28 de junio de 1837, se han agolpado con armas a la cárcel publica de esta villa, ocho esclavos i dos libres prófugos compañeros, de las esclavas, y cometieron el escandaloso atentado de sacarlas, a despecho de las amonestaciones, y medida que para ahuyentarlos prestó el jefe político. ${ }^{35}$

Ni bien fueron capturados los osados esclavos y negros libres, el juez tomó la siguiente decisión:

Los esclavos Micaela y [...] Ramires, María Antonia Rivera, Cesilia Losano, Maria Victora, Andrea Alvares, Joaquin Campo, y Josefa Gusman no han cometido otro crimen que la constitución de una vida común, oculta y fujitiva con los delincuentes enunciados -estos fueron absueltos pero bajo la condición de ser devueltos a sus amos y- condenece a Pedro Jose cruz, Manuel Josefano, Felipe molina,Valentin Lopez y Monico Abadia a cinco años de presidio en la fortalesas del Chagues. ${ }^{36}$

Las cuadrillas de esclavos y aquellos que vivían como fugitivos en espacios marginales emplearon diversas formas de boicot que implicaban desde ralentizar los trabajos hasta hurtar herramientas, animales y producir motines. A modo de ejemplo se puede citar el caso de Emigdio Carabali, acusado por los señores esclavistas Sergio y Julio Arboleda, Ignacio Ortiz y Braulio Bello de vagancia, hurto y sublevación, quienes mencionan que: "es un individuo perjudicial a la sociedad que no tiene arte, oficio ni beneficio, hacienda o renta de donde le venga ciertamente la subsistencia; i que por tal motivo se mantiene robando a los propietarios sus ganados, de cuyo delito no ha sido posible convencerlo hasta ahora por la facilidad que

35. ACC, Popayán, Fondo República, Criminal, signatura 7390 (Rep. JV-1 cr).

36. ACC, Popayán, Fondo República, Criminal, signatura 7390 (Rep. JV-1 cr). 
tienen en su ejecución y ocultamiento”. Además, indican que es de malestar para las haciendas y mal ejemplo para los esclavos, tal como sucediera "por los años de 1845 i 46; que por su insubordinación se hizo insoportable en la hacienda, pues llego hasta promover un motin [...] entre los demás esclavos contra el mayordomo quien tuvo que defenderse con armas"; ${ }^{37}$ su destino fue el ejército del cual se fugó.

Emigdio, que había sido capturado, negó todas las acusaciones y manifiestó tener veinticinco años, ser de oficio labrador y vecino de la parroquia de Popayán. Declaró que su único delito es "recibir en el monte a unos negros huidos con un pedazo de carne de una res que se habian hurtado de la hacienda de la Balsa" ${ }^{38}$ Más allá de las mutuas acusaciones, lo interesante del caso es el despliegue de estrategias individuales y colectivas de perturbación que asoman con toda claridad en la acción de los zurriagueros.

A consecuencia de todo lo anteriormente dicho y otros eventos más, el 7 de marzo de 1849 es fijado como la fecha que inaugura el intersticio liberal y coincide con el potencial emergente de los zurriagueros. Según Margarita Pacheco, lo que condujo a los zurriagueros a lanzarse a las calles para ajustar cuentas, reivindicar derechos y demandar condiciones de subsistencia fue la apropiación por parte de la aristocracia terrateniente caleña de espacios considerados como bienes públicos por los sectores populares. Señores como "el Dr. Cayzedo cercaron unos terrenos y caminos utilizados por los habitantes para extraer frutos, pastos, leñas, aguas; lo que provocó el levantamiento de la llamada 'plebe'. Durante una noche derribaron el cercado que el señor Cayzedo había puesto a los senderos". 39

Con relación a esto, el Ariete, periódico conservador, publicó:

En Buga se vieron a los cuadrilleros pasearse con orgullo, armados en varias partidas, el 3, el 7, el 24 i el 31 de marzo principalmente; i cometer en dichos días varios atentados contra las personas [...] El 3 se suscitó un tumulto contra la sociedad de amigos del orden, haciendo creer al Gobernador i al jefe político que en ella se vertían expresiones subversiva del orden; porque un orador calificó de horrendo el 7 de marzo [...] El 7 se produjo los mismos actos celebres, con que por todas partes se ha hecho conmemoración del horrible atentado [...] Esto ha sido decir a los esclavos como en 1841; asesinad a vuestros amos; i a los deudores; borrad vuestras cuentas con la sangre de vuestros acreedores. ${ }^{40}$

La acción social de las cuadrillas fue tan amplia que en Cali y la provincia de Buenaventura se informaba el 3 de abril de 1856: "De cuatro meses a esta parte se ha visto frecuentemente alarmada esta ciudad, a consecuencia de rumores $i$ avisos, que presentaban [...] aun inminente golpe [...] ejecutado por un grupo

37. ACC, Popayán, Archivo Muerto, paquete 47, legajo 84.

38. ACC, Popayán, Archivo Muerto, paquete 47, legajo 84.

39. Margarita Pacheco, La fiesta liberal en Cali (Cali: Universidad del Valle, 1992) 217.

40. Ariete (Cali) 7 de abril de 1850. 
de hombres, famosos asesinos algunos de ellos i de indómitos i feroces instintos". ${ }^{41}$ Tales rumores no eran infundados, puesto que:

una numerosa cuadrilla de malhechores en el caserío de las Pavas [...] Fueron asaltadas y robadas por ella (la cuadrilla) [...] San José, las Tapias y Bolivia, de cuyos hatos tomaban diariamente el ganado necesario para su subsistencia. El señor José Joaquín Caicedo fue también atacado en su casa de Guavinas por una partida numerosa, que sustrajo i robó unos cuantos efectos de dicho Sr. Caicedo. - El conocimiento de las zonas permite que la cuadrilla— $[\ldots]$ se reúnen i se dispersan al amparo de las tinieblas. ${ }^{42}$

Estas acciones y noticias sobre asaltos, asonadas y avisos de invasiones colectivas quedaron ampliamente registradas en la prensa de la época. Por ejemplo: "El domingo fue asaltado en Pambio el señor Carlos Maria Cordova por seis hombres con lanza en manos [...] Hasta ahora no se descubre los autores, nosotros nos atrevemos a creer que no ha sido hombres del campo sino mui de la ciudad". Luego de haber hecho el seguimiento del caso, se indicó que "Han sido aprendidos i ya están en la cárcel de esta ciudad el cabecilla i dos mas de los que formaban la cuadrilla de bandidos que asalto i robo últimamente al señor Carlos Maria Cordova" ${ }^{43}$

La respuesta no se dejó esperar, la élite acusaba a los negros de promover la delincuencia y la vagancia, andando en cuadrillas armadas y, lo peor, respaldados por la élite política liberal, la cual era permisiva o ignoraba sus acciones. ${ }^{44}$ Más allá de las acusaciones, en las provincias del Valle del Cauca, Buenaventura y Chocó una alianza entre cuadrilleros y liberales fue brotando en la medida que ambos se identificaron en sus objetivos políticos. Así lo menciona la prensa:

En Cali, en Buga, en Palmira, hemos visto durante este mes, repetidas unas mismas tumultuarias escenas, de la que resalta siempre, que cuadrillas de hombres malos, de estos que según las nuevas ideas de democracia, que hoy predican los liberales rojos; forman lo que ellos llaman pueblo soberano, se han armado por sí mismos, o por orden de las autoridades políticas, bajo el pretesto de temerse una conmoción, apoyado por el honrado patriota Antonio Boso [...] En alarma continua se han mantenido estas poblaciones en todo el aciago mes, viendo ocupada las calles por las noches por partidas armadas, que insultaban i amenazaban a los ciudadanos más respetables, $\mathrm{i}$ que parecían colocar el lance de una justa resistencia, prevalidos por el mayor número que por el momento tenían reunido, i seguro de la impunidad por las autoridades políticas, que bien merece ser traducida por convivencia i complicidad. ${ }^{45}$

41. El Constitucional de Buenaventura (Cali) 3 de abril de 1856.

42. El Constitucional de Buenaventura (Cali) 3 de abril de 1856.

43. El Constitucional de Buenaventura (Cali) 3 de abril de 1856.

44. Andrés Pabón, "Criminalización de la vagancia durante los inicios de la formación republicana en Colombia”, Pensamiento Jurídico 39 (2014): 203-227.

45. Ariete (Cali) 7 de abril de 1850. 
La participación de los afrocaucanos en eventos de protestas toma con claridad una connotación política tras el vínculo que se va gestando entre líderes políticos y cuadrillas. James Sanders aborda con claridad la alianza entre el partido político liberal y el pueblo, el cual no solo incluía a la población afrocaucana, sino también a artesanos, campesinos e indígenas de la zona. Según Sanders,

la alianza que se desarrolló entre las élites liberales caucanas y los liberales subalternos exhibió tres dimensiones: primero, era una negociación sobre las estructuras sociales, políticas y económicas de la región; segundo, era un soporte tanto militar como político [...]; y tercero, era la confluencia del concepto liberal de ciudadanía con la apropiación de tal identidad por parte de los afrocolombianos. ${ }^{46}$

Esta alianza no solo atemorizaba a los amos y propietarios por las asonadas, incendios y robos ejecutados, sino también por la capacidad de incidencia en las decisiones políticas de estos grupos. Esto es constatable en la presión que ejerce un grupo de hombres armados sobre el nuevo gobernador de Quindío y Tuluá, exigiendo que deponga su intención de posicionarse en el cargo:

Anoche salieron nuevas partidas numerosas insultando al nuevo Gobernador (de Quindío) — Vicente Gutiérrez-, hoi ha tomado posesión, i en el acto, Carrillo I Pizarro con un grupo de hombres armados acudieron a la plaza según dicen con el fin de matar a Gutiérrez. El señor cura creo que trató de disuadir a Pizarro, i actualmente que van hacer las dos de la tarde, está sola la plaza i las partidas han salido de la ciudad, i se hallan a los alrededores. Dicen que si Gutierrez no dimite el mando, i se pronuncian antes de las cinco de la tarde, por manera que si no mejora el aspecto amenazante de los amotinados, habrá un descalabro. ${ }^{47}$

Al tomar parte de aquello a lo que tenían derecho por naturaleza, pero que les era negado por quienes detentaban el poder, daban una muestra clara de la capacidad afrocaucana de presionar e incidir en los asuntos políticos. Este potencial llegó a ser temido por la élite y estigmatizado como delictivo. Los datos oficiales no contabilizan el número de acciones reivindicativas de este grupo, pero sí presentan la intensidad de los actos criminales. Si bien no existen datos suficientes para establecer una tendencia de los actos denominados delictivos, es posible observar el malestar social por medio del gran número de noticias al respecto.

$\mathrm{Y}$ aunque las revueltas fueron sofocadas por las milicias del gobierno, el hecho trascendental es sin duda la unión de las cuadrillas con las facciones liberales. La alianza entre zurriagueros y líderes políticos se concreta con la formación de círculos, clubes y asociaciones denominadas en su conjunto sociedad patriótica, que para 1849 cambió de nombre y comenzó a llamarse Sociedad Democrática.

46. James Sanders, “'Ciudadanos de un Pueblo Libre’: liberalismo popular y raza en el suroccidente de Colombia en el siglo XIX”, Historia Crítica 38 (2009): 172-203.

47. Gaceta Oficial del Cauca (Popayán) 24 de enero de 1860. 


\subsection{Participación asociativa: "de bandidos a ciudadanos"}

Bajo el estigma de delincuentes, bandidos y vagos, las cuadrillas de esclavos y negros libres incursionaron en la escena pública-política con un balance aparentemente negativo, toda vez que la rebelión y el mandato presidencial de José María Obando, en conjunto con el gobierno del general José Hilario López, fueron frenados por la reacción conservadora que retoma el poder entre 1855-1858 con los mandatos de Manuel María Mallarino y Mariano Ospina Rodríguez. Ante esta situación, los negros de las provincias del sur tuvieron que abandonar algunas de sus pretensiones políticas. No obstante, habían conquistado legalmente la libertad, lo que de facto ya era una práctica recurrente. Esta fue decretada el 1 de mayo de 1851 y ejecutada el 1 de enero de 1852.

Otro resultado importante de las protestas zurriagueras fue la alianza entre la población afrocaucana y los políticos liberales locales. Esta alianza se produjo sobre todo en la región delValle del Cauca y en las provincias de Buenaventura y Cauca, y se concretó a partir de la conformación de sociedades democráticas integradas básicamente por negros y dirigentes liberales. Los señores conservadores, que no eran otros que los esclavistas, terratenientes y propietarios, vieron como una amenaza la proliferación de las organizaciones liberales y señalaron:

\footnotetext{
los liberales rojos por todas partes forman sociedades con el nombre de democráticas, i que el interés que los mueve, el fin que los guía, i el resorte activo que los estimula es únicamente el de apoderarse del pueblo, para que les sirva de instrumento i de apoyo a su ambición, alucinándole con los nombres májicos de la libertad; igualdad, fraternidad. ${ }^{48}$
}

Esta descripción deja ver al pueblo como manejado por los liberales, no obstante, es claro que los intereses de los afrocaucanos hallaban eco en las ideas de libertad, igualdad y fraternidad. Precisamente, los cuadrilleros o los negros libres son los que mayoritariamente integraban las sociedades democráticas, tal como se evidenció en Cartago donde "los negros que en su mayoría componen esta sociedad, se aproximaron a la portería del Colejio donde aguardaban la hora deseada para ver si ya había venido la lei que daba la libertad a los esclavos, i autorizaba el comunismo: al fin llegó el escribano José María Caicedo Navia, a quien se le avisó que la sala estaba en el oscuro por que no había alumbrado", 49 al final la sesión fue suspendida y retomada el día siguiente.

Aunque quedó claro que las denuncias conservadoras contenían un tinte despectivo y agreste sobre la participación de los afrocaucanos en las sociedades democráticas y que, además, censuraban la acción de los políticos liberales, es interesante observar en ellas el reconocimiento explícito de la innegable acción política de

48. Ariete (Cali) 3 de noviembre de 1849.

49. Ariete (Cartago) 23 de Julio de 1850. 
los negros en favor de sus demandas. Tal como sucedió en Buga la noche del 7 de marzo de 1850 cuando se conmemoraba el primer año del triunfo liberal:

Una de esas cuadrillas, capitaneada por el presidente de la sociedad democrática, rodeó en la calle, insultó i amenazó a los hombres ciudadanos Dr. Mariano Ospina i Crisanto Valenzuela, secretario el uno i escribiente el otro del tribunal; i el comandante de la guardia nacional, auciliar, a la cabeza de una partida de individuos de ella, tuvo el arrojo de amagar contra el virtuoso anciano Sr. Joaquín López, que, aun valetudinario i casi ciego, salio de su casa a averiguar las causas del desorden i de la alarma que se notaba; i en presencia del Gobernador i del Jefe político lamentaba, cuando fue insultado, los excesos a que cuatro hombres perversos estaban conduciendo al pueblo de Buga. ${ }^{50}$

La facilidad con que las cuadrillas aparecían y desaparecían generó estragos en los espacios reservados para los propietarios; asimismo, condujo a que los señores amigos del orden cuestionaran:

con suma franqueza i enerjia los cargos de autoridad por la tolerancia con que permitían, que partidas armadas anduviese por las calles, turbando el orden i la tranquilidad de la ciudad, i amenazando de muertes a los hombres sensatos, calificados de conservadores; porque se han repartido por las autoridades políticas armas a los hombres a listados en uno de los partidos en que estamos divididos $[\ldots]$ porque todo esto se hace a presencia de las autoridades políticas, i aún se teme que con su secreta aprobación, pues, según se dice, ellas saben anticipadamente los planes de los que suscitan sonadas, i se esperan con indiferencia los resultados. ${ }^{51}$

Comienza de esta forma una alianza entre políticos y cuadrilleros, constatable por la mutua colaboración entre las partes. Esta alianza es censurada en juicio por los señores esclavistas Julio Arboleda, Manuel y Juan Luna y Manuel Ibáñez miembros de la sociedad popular o de amigos del orden como se les llamó a las sociedades conservadoras - Estos señores afirmaban que "algunas de las mismas autoridades se han visto, de noche, capitaneando una turba que nos ha amenazado a voz en cuello con gritos de muerte", por lo que lanzan una acusación al gobernador de la provincia de Popayán, Manuel José Castrillón, en la que hacen la denuncia de:

tomar armas de los depósitos del Estado i ha armado con ellas, con infracción de las leyes, a los hombres de su confianza. Corre como cierto, que el gobernador de la provincia ha llamado a esos hombres a su propia casa, i en sesión nocturna, ha exitado sus pasiones malévolas contra la parte inerme, indefensa i pacifica de la poblacion. El gobernador de la provincia ha formado con esos hombres, asi armados i exitados, una sociedad llamada "Democratica" cuyo estatutos son para todos desconocido [...] ¿Cómo sucede que la autoridad pública, encargada de nuestra

50. Baluarte (Cali) 11 de marzo 1850.

51. Ariete (Cali) 7 de abril de 1850. 
seguridad, escoja antes hombres de su confianza, los arme, los reúna en medio de las tinieblas, los exite, i, conociendo en mucho de ellos los enemigos del gobierno civil en 1839, 40, 41 i 42, i sabiendo cuales son sus sentimientos para con nosotros, los enrejimente armados para soltarlos despues, sin piedad, sobre los demas, que estan inertes, indefensos, i sin mas proteccion en el Universo que la de Dios? ${ }^{52}$

Igual acusación recibe el gobernador de Palmira al afirmarse que se encuentra "mesclado U. con esa jente libertina ha perdido la delicadeza que siempre le ha ganado el aprecio de los hombres honrados... bien sabe U. que las armas i los aperos de guerra que tiene este canton se hallan en poder de U.i de los rojos" ${ }^{53}$

En síntesis, esta alianza que los conservadores del Cauca fustigaron y censuraron, tenía un claro propósito con fines distintos. El propósito en común era lograr la ciudadanización de los afrocaucanos, en tanto que los fines de este grupo trataban sobre el contenido de igualdad social y económica de una categoría expresamente política, el fin liberal era conducir a la "plebe" a una ciudadanía que les diera legitimidad política. El 7 de marzo de 1849 fue la fecha insigne para celebrar la alianza política y la incursión del pueblo en el escenario político. Es una fecha "que no debe pasar desapercibida, porque forma parte de esos grandes acontecimientos en que un pueblo es autor [...] Ellos se acordaron el dia en que empezaron a ser ciudadanos porque tomaron i toman parte en la causa pública". ${ }^{54}$

\subsection{Participación electoral: de ciudadanos de sombra a ciudadanos políticos}

En el marco de la disputa por la ampliación de la ciudadanía, la élite criolla estableció el voto como el elemento diferenciador entre los miembros de pleno derecho y la plebe. El ciudadano era aquel que podía elegir y ser elegido bajo ciertos requerimientos jurídicos y de hecho. Con el intersticio liberal, los políticos nacionales y locales del partido rojo procuraron apoyo de las bases sociales para generar transformaciones político-económicas. Con la constitución de 1853 se declara el voto secreto, directo y universal para varones; sin embargo, los requerimientos de hecho en una sociedad jerarquizada y excluyente como la caucana pesaron más que una orden escrita.

Los asuntos público-políticos en la región del Cauca estaban en manos de familias pudientes. Entre sus intenciones estaba tratar de impedir que clases emergentes se incluyeran y alteraran el statu quo. Durante la primera mitad del siglo XIX el voto era reducido y se manejaba mediante redes y alianzas que garantizaban no solo ganar las elecciones, sino permanecer en el poder; era común ver las mismas figuras rotando en los diferentes cargos públicos. El caso de Popayán lo ilustra bien, pues las familias Mosquera-Arboleda en ocasiones se enfrentaban entre sí,

52. ACC, Popayán, República Judicial, Fondo Civil, signatura 7970 (Rep. JV -4 cv).

53. Ariete (Cali) 11 de abril de 1850.

54. Baluarte (Cali) 11 de marzo 1850. 
pero cuando eran amenazados cerraban filas y hacían que el acceso y ascenso de terceros por las vías institucionales fuera prácticamente una quimera.

Ver la participación electoral desde este ángulo cerrado y restrictivo conduce a afirmar que los afrocaucanos no tuvieron ninguna oportunidad de incidir en las prácticas electorales; sin embargo, la participación electiva no solo comprendía la acción de depositar una papeleta, sino que englobaba acciones a priori (promoción y publicidad de candidato, nexos y redes de votantes y no votantes) y a posteriori (escrutinio, resultados, aceptación o rechazo de los mismos). Con esta misma idea, y pensando en las diversas formas de incidencia que pudieron desarrollar los afrocaucanos, es menester abordar las jornadas electorales en su conjunto, lo que involucraba un mayor número de actores, además de los votantes, que participaban o tomaban parte de. Esto lo aclara Tomas Bañez, cuando afirma que: "la participación es en un primer sentido integrador consistente en 'ser partícipe de', es decir, recibir prestaciones o disponer de servicios; y un segundo sentido consistente en 'tomar parte de', que se refiere a la capacidad colectiva para promover iniciativas de dinamización de la vida social". 55

En este orden de ideas, se puede afirmar que para este entonces los afrocaucanos poseían un repertorio amplio devenido de las experiencias de luchas; que habían participado activamente en las guerras civiles y desarrollado allí nociones de justicia y derecho, y que, además, habían diseñado estrategias sistemáticas de acción social que involucraban boicot, rebeliones, asonadas y protestas sostenidas. A todo esto es posible sumarle la alianza pactada con el partido liberal a través de las sociedades democráticas. Este escenario permitía a los afrocaucanos conocer la trascendencia de las jornadas electorales. Por lo que no fueron en ninguna forma actores pasivos, limitados por su exclusión al voto, sino que desplegaron prácticas individuales y colectivas que afectaban el desarrollo electivo.

A modo de ejemplo es posible citar el caso que sigue: la declaración de nulidad de las elecciones de diputados en Barbacoas en 1857, donde se acusa que la elección del señor Pablo estaba alterada, pues se imputaba a:

un ciudadano de haber ejercido coacción sobre un elector o sobre un jurado al tiempo de las votaciones del Sr. José [...] embriagándose a un miembro del primer jurado [...] para impedir que asistiese el dia del escrutinio general además armar de fusiles [...] al resguardo i otros individuos i colocarlos al frente del jurado el dia del escrutinio jeneral sin que hubiese el mas pequeño motivo o rumor de turbarse el orden publico. ${ }^{56}$

El informe completo señala que indígenas y grupos de malhechores negros ejercían acciones coercitivas sobre los votantes y los jurados y, de esta forma, propiciaban la elección del candidato de su preferencia.

55. Tomasa Bañez, “Ciudadanía y participación”, Ciudadanía. Dinámicas de pertenencia y exclusión, coords. María Bernuz y Raúl Susín (Logroño: Universidad de la Rioja, 2003) 99.

56. ACC, Popayán, Fondo República, Archivo Muerto, paquete 55, legajo 94. 
Acciones como la anterior fueron constantemente denunciadas en las jornadas electorales en las cuales cuadrillas con armas se apostaban cerca de los lugares de votaciones y ejercían presión sobre las decisiones electivas. Así se deja ver en el informe que emite Ángel Miguel a Tomas Cipriano de Mosquera, gobernador del Estado del Cauca, sobre las elecciones realizadas el 20 de febrero de 1859 en Barbacoas. En él se afirma que "el dia 20 del presente al tiempo de las elecciones, conociendo los rojos la mayoría del partido contrario, se propusieron alterar el orden por medio de los negros para ver si podían sacar ventajas a la sombra de los trastornos". ${ }^{57}$ Lo interesante de esta representación es que los señores de la élite reconocieron la capacidad de estos grupos no solo para perturbar el orden, sino también para incidir en las decisiones electivas.

Por tanto, aumenta el interés sobre las jornadas electorales y los mecanismos para trasmitir la información sobre estas, al igual que las estrategias y acciones a ejecutar en caso de que los resultados fueran contrarios a sus intereses. Uno de los casos que ilustra esto se retrata en el escrito que envía José María Correa a Tomás Cipriano de Mosquera en el que le informa:

...fui a Cali i el dia antes de llegar me alojé en la Hacda de "Mulado" i el mayordo de ellos me informó que el negro Victorio había estado allí ocho días despues de las elecciones i había tratado con los negros de aquella hacda i de la San Marcos, i los había dicho que se había "ejercido" la elección de Palau en los pueblos de Palmira, Cali, Buga, Guacarí, Cerrito, i que en caso de perderlas hecharian abajo al gral Mosquera. ${ }^{58}$

La participación política de los afrocaucanos no solo se expresó en acciones coercitivas o violentas, sino que también la ejercieron como verdaderos ciudadanos en las urnas. El siguiente caso señala a un grupo de negros de Almaguer como responsables de un ataque al señor Ramos y a su esposa, lo trascendente de la noticia es que identificaron a este grupo como mazamorreros que habían ido a depositar su voto:

Verdad es que Uds. Dtor. Ramos ha hecho circular las noticias de que el dia 24 [...] de setiembre por la noche fue sorprendido por cuatro individuos desconocidos, armados de palos, cuchillos i espadas con guarnición, asegurando la mujer del dtor. Sr. Ramos, que el individuo que la abía cojido era negro pasudo por que le abia sacado la caveza, i que además le había dado un mordisco en la barriga, atribuyendo que eran los morenos de la hacienda de mazamorras, que habian salido a dar su voto para las elecciones de diputados, por cuya razón supo el que informa por voca de algunas personas, que los espresados negros habian sido. ${ }^{59}$

57. ACC, Popayán, Sala de Mosquera, carpeta 17, doc. 28. 960.

58. ACC, Popayán, Sala de Mosquera, carpeta 1, doc. 36.015.

59. ACC, Popayán, Fondo República, Archivo Muerto, paquete 57, legajo 24. 
Otra información que ha quedado registrada y que ilustra la participación electoral de los negros libertos es la que Juan Aparicio suministra al gobernador del estado del Cauca sobre las elecciones en Buga, en ella indica que

la mayor parte, o casi todos los que pertenecen al partido liberal en el Cauca son jente del pueblo bajo $[\ldots]$ i negros $[\ldots]$ que se comprometen a botar por el que ellos les dicen, manifestándose conbencidos por las razones que se les esponen. i aun reciben la boleta que se les da de botación, entregan esta boleta a uno de sus cabecillas [...] en Cali, Palmira, Buga todas las elecciones las gana el partido liberal. ${ }^{60}$

Más allá de la presunta manipulación, lo que le interesaba a este señor era resaltar el ejercicio electoral de los negros en un escenario aparentemente restringido para ellos.

La consolidación del proceso de ciudadanización de los afrocaucanos se evidenció con más claridad en el uso que estos dieron a la ciudadanía para exigir derechos y resistir abusos fiscales. Por ejemplo, el caso de los habitantes de la hacienda de San Julián quienes el 15 de octubre de 1853 remitieron una petición al gobernador de esta provincia:

Los infrascritos vecinos del distrito parroquial de Caloto, i habitantes en la hacienda de san Julian, a que pertenecimos antes como esclavos, ante $\mathrm{Ud}$, en uso de nuestros derechos como ciudadanos representamos: que desde que dejamos de depender del señor que se titulaba nuestro amo, i entramos por ministerio de la lei en la categoría de hombres libres, nuestra condición que debiera ser feliz i corresponder el fin humanitario i filantrópico que el govierno se propuciera $[\ldots]$ ha llegado a ser [...] igualmente destestable; [...] por que nos ha tocado por nuestra desgracia, quedar bajo el dominio de un pueblo que nos hostiliza con repetidas i frecuentes exacciones, que nos persigue bajo cualquier pretesto, que nos quita el tiempo para trabajar ocupándonos inmensamente en cervicios locales, i que nos quiere combertir en esclavos todabia, i de peor naturaleza de lo que antes fuimos. Ese pueblo es Calóto; i su govierno parroquial nuestro tirano. Alli se nos éxije un real de tributo mensual a cada uno de nosotros, tres reales más por el travajo personal, i con el nombre de subcidiario tres días de travajo personal que pagamos en plata cada año. Se nos hace pagar desde tres hasta ocho reales por cada vailecito de los que nosotros acostumbramos para divertirnos; allí se nos llama cemanalmente a hacer i cervicio de presidiarios, matando los perros en las calles i haciendo la policía de limpieza de ella; alla en fin se nos tiene presente para todo cuanto pueda pribarnos de nuestro travajo i del uso de nuestra livertad. - no experimentamos otra cosa mas que - el despotismo i la tiranía mayor i mas insoportable.

Por tales razones solicitamos fervorosamente, i de la manera mas formal, que se nos agregue al distrio parroquial de Santander [...] vien sabemos señores gobernadores que Ud. No puede resolver esta solicitud, si no la legislatura provincial, pero la elavoramos a U. suplicando que en

60. ACC, Popayán, Fondo República, Archivo Muerto, paquete 57, legajo 24. 
fuerza de la justicia [...] i de los hechos referidos se digne U. pasarla a la lejislatura en su próxima reunión apoyándola con un informe favorable. ${ }^{61}$

Una comisión atendió la solicitud de los ciudadanos y, tras el estudio del caso, sostuvieron que "luego como aquellos individuos entraron a gozar de los mismos derechos que todos los demas ciudadanos i fueron requeridos con las obligaciones a que quedaban sujetos comenzo entre ellos una murmuracion que muchos temiamos fuese el preludio de una cosa sangrienta". Por lo que no es posible que los negros libres quieran ostentar los derechos ciudadanos, pero sin asumir las responsabilidades que implican, alude la comisión. En tal sentido, se resuelve que los cobros estaban justificados y, con relación a la adhesión a Quilichao, se indicó que no era competencia de la comisión. ${ }^{2}$ Es claro que no hubo demasiada suerte en la petición de los habitantes de la hacienda de San Julián, pero es evidente la propiedad con que comienzan a usar la noción de ciudadanos cuando aludían a una idea de justicia que les permite protestar, en conjunto, con una noción de derecho a utilizar el producto de su trabajo que ya no pertenecía a un amo.

\section{Comentarios finales}

La ciudadanía como enclave de la acción activa de la sociedad civil en los asuntos público-políticos constituye una plataforma de voces reivindicativas y de demandas sociales, políticas y económicas. La apropiación del concepto de ciudadanía ha permitido que actores que históricamente han sido excluidos emitieran voces en pro de la inclusión.

La dimensión de inclusión / exclusión ha hecho de la ciudadanía un campo de disputas y luchas históricas por el reconocimiento y la reivindicación. La disyuntiva entre inclusión y exclusión es más notoria al abordar las dinámicas primigenias de la ciudadanía. Estas dinámicas para el caso de la Nueva Granada se gestan durante el siglo XIX, aparejado a los procesos de construcción del Estado, la nación y el ciudadano. Para este momento, se configura ya una ciudadanía en permanente disputa que excede el monopolio de un grupo en particular y conforma diversos caminos de acceso a ella. Esta ciudadanía se nutre, por un lado, de las iniciativas elitistas y, por el otro, de las acciones reivindicativas, de resistencia y de negociación emprendidas por los grupos subalternos, en este caso los afrocaucanos.

La ciudadanía desde abajo se construye por las acciones afirmativas emprendidas por los afrocaucanos que incidieron en los asuntos público-políticos. En primer lugar, incursionaron en las guerras civiles a cambio de libertad y tierra. Promesas que fueron incumplidas; no obstante, contribuyeron a forjar nociones de justicia y derecho, negadas por naturaleza, pero conquistadas por la acción participativa. De esta forma, los afrocaucanos fueron conscientes de la posibilidad de 
acceder a beneficios, llamados derechos, que redundaran en el mejoramiento de su condición de vida y posición en la sociedad.

En segundo lugar, combinaron las nociones de justicia y derecho con el potencial histórico de resistencia y la capacidad asociativa para emprender acciones de protestas que aterrorizaron a la élite caucana. En cuadrillas incursionaron en las tierras de gamonales y terratenientes que, por lo general, eran sus antiguos amos, y boicotearon las actividades de producción, promovieron asonadas e incendiaron haciendas y fincas. En tercer lugar, establecieron nexos con políticos, incidieron en las jornadas electorales y ejercieron el voto.

El potencial ciudadano de los afrocaucanos los condujo a vincularse activamente en las sociedades democráticas, conquistaron la libertad jurídica y avanzaron en ideas sobre el derecho de propiedad y la participación mediante el ejercicio del voto.

Estas prácticas ampliaron la noción de ciudadanía política, incluyendo en ella demandas sociales y exigencias económicas, lo que dio forma a una ciudadanía que escapó del dominio expreso de la élite.

\section{Fuentes}

\section{Manuscritas}

Archivo Central del Cauca, Popayán (ACC)

Fondo República

Archivo Muerto

Sala de Mosquera

\section{Periódicos}

Gaceta Oficial del Cauca (Popayán) 1860.

El Constitucional de Buenaventura (Bogotá) 1856.

Ariete (Cali) 1849-1850.

Ariete (Cartago) 1850.

Baluarte (Cali) 1850.

\section{Bibliografía}

Annino, Antonio. "Ciudadanía versus gobernabilidad republicana en México. Los orígenes de un dilema". Ciudadanía política y formación de las naciones. Perspectivas históricas de América Latina. Coord. Hilda Sábato. México: Colegio de México, 1999.

Arcos, Arleison. Ser como ellos. Esclavización, cimarronaje y republicanismo en el siglo XIX en Colombia. Medellín: El Colectivo de Investigaciones Afrocolombianas, 2014. 
Bañez, Tomasa. "Ciudadanía y participación”. Ciudadanía. Dinámicas de pertenencia y exclusión. Coords. María Bernuz y Raúl Susín. Logroño: Universidad de la Rioja, 2003.

Carvalho, José Murilo. "Dimensiones de la ciudadanía en el Brasil del siglo XIX". Ciudadanía política y formación de las naciones. Perspectivas históricas de América Latina. Coord. Hilda Sábato. México: El Colegio de México, 1999.

Casarán, Sabas. "Negros en Colombia invisibilidad y presencia”. El negro en la historia de Colombia. Primer simposio sobre bibliografía del negro en Colombia. Ed. Fundación Colombiana de Investigaciones Folclóricas. Bogotá: Fondo Interamericano de Publicaciones de la Cultura Negra de las Américas / UNESCO, 1983.

Colmenares, German. Popayán: una sociedad esclavista, 1680-1800. Bogotá: La Carreta, 1997.

Elias, Norbert. El proceso de la civilización: investigaciones sociogenéticas y psicogenéticas. México: Fondo de Cultura Económica, 2015.

Helg, Aline. "Raíces de la invisibilidad del afrocaribe en la imagen de la nación colombiana: independencia y sociedad, 1800-1821". Museo, memoria y nación. Misión de los museos nacionales para los ciudadanos del futuro. Comps. Gonzalo Sánchez y María Emma Wills. Bogotá: ICANH / IEPRI, 2000.

Huntington, Samuel y Joan Nelson. No Easy Choice: Political Participation in Developing Countries. Cambridge: Harvard University Press, 1976.

Jaramillo Uribe, Jaime. "Esclavos y señores en la sociedad colombiana del siglo XVIII”. Anuario Colombiano de Historia social y de la Cultura 1 (1963): 3-62.

Jiménez Meneses, Orián y Edgardo Pérez Morales. Voces de esclavitud y libertad. Documentos y testimonios. Colombia, 1701-1833. Popayán: Universidad del Cauca, 2013.

Kemner, Jochen. “¿Eran ciudadanos los afrodescendientes libres en las sociedades esclavistas? Cuba, Brasil y Estados Unidos en el siglo XIX”. Revista ecuatoriana de historia (2012) 36:9-38.

Marshall, Thomas. Ciudadanía y clase social. Madrid: Alianza Editorial, 1998.

Marx, Karl. El dieciocho brumario de Luis Bonaparte. Madrid:Alianza Editorial, 2003.

Mina, Mateo. Esclavitud y libertad en el valle del río Cauca. Bogotá: Fundación Rosca de Investigación y Acción Social, 1975.

Múnera, Alfonso. El fracaso de la nación: región, clase y raza en el Caribe colombiano (1717-1821). Bogotá: Banco de la República, 1998.

Pabón, Andrés. "Criminalización de la vagancia durante los inicios de la formación republicana en Colombia”. Pensamiento Jurídico 39 (2014): 203-227.

Pacheco, Margarita. La fiesta liberal en Cali. Cali: Universidad del Valle, 1992.

Palti, Elías J. El tiempo de la política. El siglo XIX reconsiderado. Buenos Aires: Siglo XXI, 2007.

Posada, Eduardo. “Abolición de la esclavitud”. Revista Jurídica 176 (1925): 126-133.

Putnam, Robert. Bowling Alone. The Collapse and Revival of American Community. 
New York: Simon and Schuster, 2000.

Quiroga, Hugo. "Ciudadanía y espacio público. Debates y perspectivas”. Revista Venezolana de Ciencia Política 27 (2005): 5-32.

Somers, Margaret. "La ciudadanía y el lugar de la esfera pública: un enfoque histórico”. Ciudadanía: justicia social, identidad y participación. Comps. Soledad García y Steven Lukes. Madrid: Siglo XXI, 1999.

Sanders, James. Contentious Republicans, Popular Politics, Race, and Class in NineteenthCentury Colombia. Durham / Londres: Duke University Press, 2004. . “Ciudadanos de un Pueblo Libre': liberalismo popular y raza en el suroccidente de Colombia en el siglo XIX”. Historia Crítica 38 (2009): 172-203.

Tannenbaum, Frank. Slave and Citizen: The Negro in the Americas. Boston: Beacon Press, 1992.

Tilly, Charles. “¿De dónde vienen los derechos?”. Revista Sociológica 55 (2004): 273-300.

Tovar Pinzón, Hermes y Jorge Tovar Mora. El oscuro camino de la libertad. Los esclavos en Colombia, 1821-1851. Bogotá: Universidad de los Andes, 2009.

Turner, Bryan. "Outline of a Theory of Citizenship”. Sociology 24.2 (1990): 189217.

Valencia Llano, Alonso. Dentro de la ley. Fuera de la ley. Resistencias sociales y políticas en el Valle del Cauca. 1830-1855. Cali: Centro de Estudios Regionales Región / Universidad del Valle, 2008.

Zuluaga, Francisco. Guerrilla y sociedad en el Patía: Una relación entre clientelismo político y la insurgencia social. Cali: Universidad del Valle / Editorial Facultad de Humanidades, 1993. 